\title{
A Produção Discente e o Panorama Temático dos Trabalhos de Conclusão de Curso de Pedagogia da UEL (2008-2016)
}

\section{Students' Production and the Thematic Overview of UEL Pedagogy Course Final Papers (2008-2016)}

\author{
Rodrigo Alexandre Cavalarini Faustino; ${ }^{\mathrm{a}}$ Rosiclea Rodrigues Silva; ${ }^{\mathrm{a}}$ Simone Burioli Ivashita*b \\ ${ }^{a}$ Universidade Estadual de Londrina. PR, Brasil.

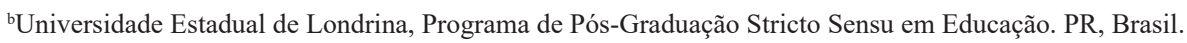 \\ *E-mail: sivashita@uel.br. \\ Recebido em: 28/03/19; Aceito em: 31/07/19
}

\begin{abstract}
Resumo
Este artigo tem por objetivo discutir a formação de professores. A pesquisa teve como enfoque principal a produção dos discentes, que defenderam Trabalhos de Conclusão de Curso de Pedagogia, entre os anos de 2008 e 2016, na Universidade Estadual de Londrina, no Norte do Paraná. O caminho metodológico se apoiou na construção de fichas catalográficas para dar organicidade ao material levantado, e a partir desta organização, alocam-se os trabalhos por área de pesquisa e tema. Como resultado se têm 664 Trabalhos de Conclusão de Curso divididos em sete áreas de concentração: Didática, Educação Infantil, Anos Iniciais, História da Educação, Filosofia da Educação, Psicologia da Educação e Política e Gestão da Educação. As primeiras observações são de que a produção não é homogênea, mas permite vislumbrar que a área mais buscada pelos discentes foi Psicologia da Educação, que concentra 157 trabalhos e as áreas menos buscadas foram Filosofia e Educação e Anos Iniciais, com 34 e 32 trabalhos respectivamente. A importância desse tipo de pesquisa se concentra na perspectiva de apresentar um panorama do que vem sendo pesquisado entre os alunos do curso, identificando os temas mais visados e as lacunas encontradas ao longo da pesquisa.

Palavras-chave: Formação de Docente. Formação Discente. Iniciação Científica.
\end{abstract}

\begin{abstract}
The purpose of this article is to discuss the teachers' training through the research carried out in the project of Scientific Initiation during the graduation course. The main focus was the students' production who defended their Pedagogy Final Paper, between 2008 and 2016, at the State University of Londrina, in the north of Paraná. Our methodological path was based on the catalogs construction to give organicity to the material raised, and from this organization, works by area of research and theme were allocated. As a result there were 664 Final Papers divided into seven areas of concentration: Didactics, Early Childhood Education, Early Years, Education History, Education Philosophy, Education and Policy Psychology and Education Management. The first observations are that the production is not homogeneous, but allows us to glimpse that the area most sought by the students was Educational Psychology that concentrates 157 studies and the least sought areas were Philosophy and Education and Initial Years, with 34 and 32 studies respectively. The importance of this type of research focuses on the perspective of presenting a panorama of what has been researched among the students of the course, identifying the most targeted topics and the gaps found throughout the research.
\end{abstract}

Keywords: Teacher's Training. Student's Training. Scientific Research.

\section{Introdução}

Ao longo dos anos da graduação são oferecidos aos alunos diversas possibilidades de aprendizagem por meio das práticas, dos estudos e das pesquisas. Em diversos momentos do curso, os alunos são convidados a participarem de grupos de pesquisa, Projetos de Iniciação Científica e eventos de diversos formatos, como: seminários, colóquios, semanas temáticas, congressos, encontros, entre outros. Nesse processo formativo, os alunos vão se encontrando com os temas que mais lhes são caros e criando certa afinidade com temas que mais despertam interesse e criando certa afinidade com os objetos ou fenômeno de estudo.

Um momento de importante concentração das energias dos alunos, ao longo da graduação, é representado pela construção, desenvolvimento e apresentação do Trabalho de Conclusão de Curso - TCC. Em algum nível o TCC representa, ou pode indicar, que tipo de olhar os alunos estão desenvolvendo, ao longo da formação, quais assuntos mais causam inquietação aos alunos a ponto de suscitar questionamentos, que encontram no TCC possibilidade de levantamento de hipóteses para o desenvolvimento de um estudo e possíveis respostas.

Nessa perspectiva, considerando o TCC como uma fonte de informação, que permite a análise dos anseios dos alunos, das inquietações acadêmicas e do horizonte profissional, que estes pretendem, entende-se que levantar os temas de pesquisa, áreas com mais e menos concentração de trabalhos, pode suscitar reflexões sobre como o curso de Pedagogia da Universidade Estadual de Londrina vem sendo conduzido. Dessa forma, quais são as principais questões problematizadas pelos discentes e quais os hiatos investigativos?

\section{Desenvolvimento}

\subsection{Metodologia}

Opta-se pelo levantamento e a catalogação dos trabalhos 
de conclusão de curso recortando temporalmente o período de 2008, ano em que se iniciam as defesas de TCC no curso de Pedagogia da UEL até 2016, ano em que são disponibilizados os últimos trabalhos na página do curso. O recorte temporal se deve ao fato de que somente a partir de 2005 o Trabalho de Conclusão de Curso passa a ser obrigatório no curso de Pedagogia da UEL, pois até então o relatório do estágio era o requisito para o título de pedagogo. Cabe ressaltar que a obrigatoriedade do desenvolvimento do TCC faz parte da reformulação do curso de Pedagogia que aconteceu em 2004, porém foi implantado em 2005 e, em 2008, houve as primeiras defesas.

\subsection{Discussão}

\subsubsection{A importância da pesquisa na graduação}

O exercício da pesquisa é importante ao longo da formação acadêmica, tendo o objetivo de familiarizar e aproximar os alunos das áreas do saber, estimulando inquietações e permite criar hipóteses sobre as realidades. A pesquisa possui o objetivo de contribuir com o repertório de conteúdos, que a humanidade acumulou (e acumula) ao longo da história, por meio de métodos sistematizados, a pesquisa recolhe informações e as transforma em conhecimento. É uma forma de produzir ciência, que poderá colaborar com respostas para as necessidades da sociedade.

Há um consenso entre os educadores de que pesquisa é fundamental na formação docente, entretanto, não há uma concepção definida de pesquisa e nem um entendimento de como essa se articula com o ensino. Nas últimas décadas começaram a ganhar força visões que defendem que a formação e a prática docente devem estar articuladas à pesquisa (MARTINS; VERANI, 2012).

Castro (2002) afirma que a investigação discente, que prioriza a problematização, contribuirá para formar o espírito científico nos jovens, mas principalmente, ajudará a torná-los pesquisadores comprometidos consigo, com o outro e com o mundo, objetivando envidar esforços para minimizar as diferenças e desigualdades sociais, culturais e econômicas do país.

O TCC é o produto final da graduação e se propõe a iniciar o aluno no universo da pesquisa, embora ao longo de toda essa etapa acadêmica, também sejam apresentadas outras possibilidades de pesquisa como citado anteriormente. Conforme aponta Demo (2002), fazer ciência contribui para a formação do futuro professor, sendo um processo que contribui para emancipação e consolidação da dimensão cidadã dos envolvidos.

A prática da pesquisa em alunos [...] tem demonstrado não só a importância de ser fazer ciência, como igualmente sua face formativa, educativa e emancipatória. A arte de saber pensar é em grande parte a arte da cidadania. Cuidado metodológico não se encerra na lide científica, mas constitui profundamente o processo formativo de alunas/alunos e professoras/ professores (DEMO, 2002, p.366).
As atividades de estudo e de pesquisa ofertadas aos alunos da graduação, dentro de modelos educacionais, opostos ao tradicional, compreendem algumas qualidades que o aluno da graduação deve desenvolver, tais como: pensar reflexivamente, ser crítico, criativo e possuir capacidades de intervir transformando a realidade que o circunda, ou seja, esse aluno deve possuir uma inquietação questionadora da realidade que o leve a pesquisas e o auxilie na busca por respostas (FREIRE, 2003).

Segundo Gonçalves Filho e Noronha (2004), é no período da graduação que o aluno tende a acumular um volume apreciável de informações e questionamentos sobre os mais diversos assuntos, sejam nos textos trabalhados, em sala de aula, e utilizados para aprofundamento das discussões das disciplinas, ou pelas experiências vividas por meio do estágio e mesmo por meio das experiências em projetos de pesquisa/ensino/extensão. Os autores indicam que "o ponto decisivo nessa discussão diz respeito justamente à atividade de pesquisa no âmbito da graduação" (GONÇALVES FILHO; NORONHA, 2004, p. 61). Segundo a Lei de Diretrizes e Bases da Educação (BRASIL, 1996), os cursos de graduação devem estimular a criação cultural e o desenvolvimento do espírito científico e do pensamento reflexivo.

Os documentos oficiais, que versam sobre as atribuições dos egressos dos cursos de Pedagogia, entre as diversas atribuições, apontam que esse profissional está apto a realizar pesquisas que possibilitem a construção de saberes sobre os alunos, a realidade escolar, as questões socioculturais e comunidade, os processos de ensinar e aprender, currículo, políticas educacionais, gestão, organização do trabalho escolar, práticas pedagógicas e demais temas. Desde que o objeto ou fenômeno ocorra na área da Educação.

A formação de um profissional, que possua condições de trilhar o caminho metodológico da investigação, deve considerar a inserção dos alunos do curso de Pedagogia em atividades de pesquisa, ao longo de seu processo formativo, estendendo-se em sua formação continuada. O Trabalho de Conclusão de Curso é uma das atividades de pesquisa que os alunos realizam na graduação e possui caráter obrigatório, como requisito para a conclusão do curso, ao longo da formação existe outras possibilidades, como citado acima, porém de caráter optativo aos alunos.

Existem várias formas de divulgação da produção científica. $\mathrm{Na}$ academia especificamente, a produção universitária dos pesquisadores é usualmente divulgada por meio de artigos em periódicos, revistas científicas, eventos, livros, congressos, entre outros meios de comunicação (GONÇALVES; NORONHA, 2004). Ao longo da vida acadêmica, os alunos e demais envolvidos no processo de Educação vão acumulando conhecimentos, que necessitam, em algum momento, de uma sistematização. O conhecimento científico precisa ser compartilhado para que possa promover efeitos na sociedade, de nada serviria um conhecimento que 
permanecesse dentro das salas da academia.

$\mathrm{O}$ século $\mathrm{XX}$ apresenta alguns sinais da realização de pesquisas, cujo objeto de estudo ocorria na área educacional. Nos anos 1930, por meio da criação do Instituto Nacional de Pesquisas Educacionais, inicia-se um processo de sistematização das produções na área da Educação. O instituto foi criado por meio de Lei (Decreto-lei 580) em 13 de janeiro de 1937, inicialmente, sendo chamado de Instituto Nacional de Pedagogia. Nessa organização sistematizada, o instituto passa a se constituir como foco de produção e de difusão de pesquisas e formação em métodos e técnicas de investigação científica em Educação (GATTI, 2001).

Passam os anos e novas tecnologias surgem colaborando com as pesquisas de diversas formas, na coleta e tratamento dos dados, triangulação de informações, acesso aos conteúdos de diversas partes do mundo, em que a ciência está constantemente sendo produzida. Partindo da perspectiva de continuidade da pesquisa, que se inicia na graduação e segue na vida profissional dos egressos do curso de Pedagogia dimensão corroborada nos documentos oficiais - entende-se a seriedade com que a pesquisa deve ser encarada.

Há, atualmente, muitas pesquisas sobre a crise de identidade do curso de formação de professores. Segundo Marafelli, Rodrigues e Brandão (2017, p. 984):

Criado em 1939 para formar "técnicos de educação", sofreu inúmeras reformulações legais, corporativas e institucionais. Esse movimento de permanentes reformulações tem provocado enorme descontinuidade às tentativas de adequálo À sua "atual" função de formação de professores para a educação infantil e anos iniciais do ensino fundamental. Além disso, segundo analistas, o baixo prestígio desses cursos e da carreira do magistério tem atraído estudantes com formação escolar precária ou fortemente motivados pela ideologia do dom e gosto, que representam as antíteses da profissionalização.

Além dessas questões da formação, apontadas anteriormente, pode-se enfatizar a desvalorização, ou o pouco incentivo, da pesquisa nos cursos de formação de professores, dando ênfase exclusiva à docência e deixando a gestão e a pesquisa de lado. Tal apagamento reflete, significativamente, no perfil do profissional formado, pois principalmente, na profissão docente, é necessário o constante envolvimento com a pesquisa e conhecimento científico. Se identificar como pedagogo e perceber que sua identidade é múltipla, com variadas possibilidades de atuação requer desse profissional uma postura de pesquisador.

Sabe-se que durante o período de graduação, os discentes estão em processo de acesso à informação, formulação de questionamentos e hipóteses em relação à área estudada, pois durante essa fase se tem a possibilidade de obter experiências perante a realização de estágios, de projetos de pesquisa, de ensino e de extensão. Salienta-se que todas essas experiências somam ao processo de aprendizado, bem como contribuem para o desenvolvimento do TCC, ou seja, requisito necessário para a conclusão do curso, em especial, à obtenção do título de licenciado em Pedagogia, foco deste trabalho.

É possível observar que muitos são os casos, em que os TCC são resultado de temas despertados nos alunos ao longo de sua participação em projetos de pesquisa. Embora como bem argumentam Bodart e Torres (2018), o eixo de pesquisa em geral está presente apenas nas Universidades públicas, fato esse, o qual não garante que a pesquisa faça parte da formação acadêmica de todos os graduandos. Contudo, o autor ressalta que:

Muitas IES possuem em suas dependências núcleos ou grupos formados para a prática da pesquisa científica. Ainda que não tão bem estruturados, esses núcleos ou grupos possibilitam uma extensão universitária qualitativa, já que o universitário não se vê preso apenas ao que o docente transmite em sala de aula, podendo ir à busca de temas, objetos e métodos de aprendizagem que o interesse, obtendo, dessa maneira, formação mais completa (BODART; TORRES, 2018, p.4).

Destaca-se que é de suma importância que os discentes tenham acesso aos conhecimentos para além daqueles previstos na grade curricular. Assim sendo, são as práticas de pesquisas, que ampliam as possibilidades dos conhecimentos dos discentes. O interesse em estudar os TCC apresentados no próprio curso é decorrência da necessidade por conhecer os inúmeros aspectos enfatizados pelos discentes, identificando as suas inquietações e perspectivas quanto ao curso de Pedagogia e as temáticas mais recorrentes, quando se tem que elaborar um Trabalho de Conclusão de Curso.

Com base em Nóvoa (1999) se pode afirmar que conhecer a história da própria profissão permite ao profissional uma visão geral da área de trabalho escolhida. Nessa perspectiva, o indivíduo tem maior capacidade de analisar e refletir criticamente sobre a função que caberá a ele exercê-la.

No entanto, como ressaltam Lopes e Galvão (2005), uma fonte nunca será esgotada, pois cada historiador terá uma pergunta distinta, que o conduzirá no trabalho junto as fontes, bem como análise e interpretação dos dados encontrados. Portanto, não se procura por uma verdade absoluta em relação à temática, o que se buscou foi uma compreensão do curso de Pedagogia da UEL, considerando especificamente as produções discentes, que abordam questões do próprio curso.

\subsubsection{O curso de Pedagogia da UEL}

Para iniciar a discussão sobre o curso de Pedagogia no Brasil, cabe destacar quem já vem se dedicando a temática de reconstruir e problematizar a história do curso de Pedagogia no país: Brzezinski (1996), Gatti (1993), Libâneo (1998) e Silva (2006), entre outros.

No ano de 1939, o curso de Pedagogia foi instituído no Brasil, sendo que "para formação de bacharéis ficou determinada a duração de três anos, após os quais, adicionando-se um ano de curso de didática, formar-se-iam os licenciados, em um esquema que passou a ser conhecido como 3+1" (SILVA, 2006, p.11-12).

Em Londrina, foi no ano de 1962 que teve início o curso 
de Pedagogia, nesse período as atividades do curso estavam vinculadas com a Faculdade de Filosofia, Ciências e Letras de Londrina (FFCLL), somente a partir de 1970, o curso passou a fazer parte da Universidade Estadual de Londrina, completando 55 anos de início das atividades no ano de 2017 (ABBUD; FAVARO, 2012).

As autoras indicam que várias alterações ocorreram em todo o curso de Pedagogia no período de 1962 a 2012, caracterizando um processo de conquistas e de perdas. Apontam-se existência de três períodos bem demarcados pelos quais o curso passou:

[...] de 1962 a 1973, em que encontramos uma formação única: licenciatura em pedagogia, sistema de matrícula seriado, em um curso de 4 anos. Entre os anos de 1973 e 1992, encontramos a mudança para sistema de matrícula por disciplina (créditos) com a oferta de habilitações. A partir de 1992, o sistema de matrícula volta a ser seriado e o curso passa a oferecer primeiramente habilitações acopladas e depois de 2007 a formação do pedagogo sem explicitação de habilitações, ou seja, o curso propôs uma formação profissional única para todos os estudantes, agregando docência e gestão pedagógica nos espaços escolares e não escolares (ABBUD; FAVARO, 2012, p.25).

No ano de 2004, o curso de Pedagogia passou por uma reformulação, que implantou a atividade de TCC na grade curricular, e como dito, a partir de 2005, o Trabalho de Conclusão de Curso passa a ser obrigatório no curso de Pedagogia da UEL. Considerando o curso de quatro anos, ao findar do ano de 2008 foram realizadas as primeiras bancas de defesa dos trabalhos. Segundo Abbud e Favaro (2012, p.34), a nova proposta pedagógica indicava a necessidade de implantar "a pesquisa como um elemento integrador, que deveria perpassar todo o curso", que se consolidou por meio do desenvolvimento do TCC.

O curso de Pedagogia da UEL passou por outra reformulação, em 2010, ampliando sua duração para quatro anos e meio. A respeito dessa alteração, Abbud e Favaro (2012, p.37-38) afirmam que:

Em 2009, a coordenação da PROGRAD - Pró-Reitoria de Graduação/UEL fez cumprir em todos os cursos de graduação da universidade a norma federal, Resolução n. 03 de julho de 2007, que impunha a adequação da carga horária dos cursos na medida hora - aula 60 minutos. Os cursos na UEL trabalhavam com medida hora - aula 50 minutos, isso acarretou um déficit no cômputo de sua carga horária total. Sob essa imposição mais uma reformulação foi realizada no curso de Pedagogia da UEL, Foi necessária a extensão do tempo do curso de 4 anos para 4 anos e meio.

De acordo com as autoras, essa nova reformulação entra em vigor no ano após a norma federal, ou seja, em 2010. Em 2009, a coordenação da PROGRAD - Pró-Reitoria de Graduação/UEL fez cumprir, em todos os cursos de graduação da universidade, a norma federal, Resolução n. 03 de junho de 2007, que impunha a adequação da carga horária dos cursos na medida hora-aula 60 minutos. Os cursos na UEL trabalhavam com medida hora-aula 50 minutos, isso acarretou um déficit no cômputo de sua carga horária total. Sob essa imposição, mais uma reformulação foi realizada no curso de Pedagogia da UEL, foi necessária a extensão do tempo do curso de 4 anos para 4 anos e meio.

Segundo o Projeto Político Pedagógico do curso, a licenciatura plena em Pedagogia possibilita ao estudante atuar no Magistério para Anos Iniciais do Ensino Fundamental; Magistério para a Educação Infantil; Gestão Pedagógica em espaços escolares e não escolares e Magistério das Matérias Pedagógicas (UEL, 2010). O curso oferta 160 vagas por ano, sendo 80 no período matutino e 80 no período noturno.

Pode-se perceber, no campo educacional, um desenvolvimento mais próximo do contorno pragmático, viés reforçado por Vieira (2011). Saviani (2007) se posiciona contrário a esta leitura, pois afirma que "o caminho efetivo de introdução da pedagogia na universidade se deu pelos Institutos de Educação, concebidos como espaços de cultivo da educação encarada não apenas como objeto do ensino, mas também na pesquisa" (SAVIANI, 2007, p.17).

Abbud e Ribeiro (2015) partem do pressuposto da necessidade da pesquisa como componente essencial no fazer da universidade, de forma indissociável das atividades de ensino e extensão. A pesquisa em educação é considerada no curso, por meio de cinco disciplinas, em um total de 460 horas, cerca de $14 \%$ da carga horária total do curso: Metodologia do Trabalho Científico em Educação ( $1^{\circ}$ ano) e Pesquisa Educacional ( $2^{\circ}$ ano) com carga horária de 60 horas cada, Trabalho de Conclusão de Curso 1, disciplina ofertada no $2^{\circ}$ semestre do $3^{\circ}$ ano, com carga horária de 120 horas, TCC 2, disciplina anual ofertada no $4^{\circ}$ ano com 160 horas e TCC3, disciplina com carga horária de 60 horas ofertada no $1^{\circ}$ semestre do $5^{\circ}$ ano.

Até o ano de 2005, as disciplinas Metodologia do Trabalho Científico em Educação e Pesquisa Educacional estavam a cargo do Departamento de Ciências Sociais, e só a partir desta data passaram a ser responsabilidade do Departamento de Educação da UEL. Ambas as disciplinas têm por objetivo fornecer conhecimentos básicos a respeito de pesquisa, de forma a subsidiar o trabalho posterior de pesquisa no TCC (ABBUD; RIBEIRO, 2015).

\subsubsection{Alguns resultados}

Para organizar os dados levantados e dar organicidade aos procedimentos referentes ao desenvolvimento desta pesquisa, instituiu-se como instrumento de pesquisa o uso de uma ficha catalográfica, que foi elaborada com o intuito de contribuir para elencar os dados que se julgaram primordiais para catalogação e posterior análise dos TCC.

Os TCC dos anos 2009 a 2016 dos quais se teve acesso estão disponíveis no site do Curso de Pedagogia (www.uel.br/ ceca/pedagogia), bem como em mídia digital (CDs), que estão guardados no LEPHE - Laboratório de Ensino e Pesquisa em História da Educação. Com relação específica aos TCC do ano de 2008, estes se encontram somente nos CDs armazenados no local já mencionado. De acordo com a Deliberação da Câmara 
de Graduação no 036/2008, o desenvolvimento do TCC é obrigatório a todos os acadêmicos do curso de Pedagogia. Desse modo, é dever dos orientandos entregarem seus trabalhos gravados em mídia digital ao coordenador de TCC.

É importante destacar que, no ano de 2013, não houve apresentação oficial de TCC, ressalta-se que esse fato é decorrente do currículo de 2010, que amplia a duração do curso de Pedagogia da UEL para 4 anos e meio. Assim, a primeira turma a concluir sob esse novo currículo apresentou TCC e colou grau ao fim de primeiro semestre de 2014.

Durante o recorte temporal desta pesquisa, conseguiuse catalogar um total de seiscentos e sessenta e quatro (664) TCCs, dos quais quarenta e dois (42) desses abordam temáticas relacionadas ao próprio curso de Pedagogia da Universidade Estadual de Londrina, ou seja, são trabalhos que tomaram por objeto de estudo o próprio fazer ou percurso do curso de Pedagogia da UEL, levantando questionamentos sobre o mesmo e corroborando com informações para o entendimento e compreensão histórica do curso.

Pode-se considerar que os trabalhos, que dissertam sobre o curso de Pedagogia da instituição indicada, contribuem de maneira significativa para a (re) construção da história referente ao próprio curso. Essas produções apresentam fontes e recursos diferenciados nos quais as pesquisas se constituíram não tendo como base somente os documentos oficiais, mas apresentando um olhar mais amplo para o conceito de fonte, como, por exemplo: a História oral, o currículo, entrevistas, entre outros.

Nas palavras de Lopes e Galvão (2005, p. 41), há uma verdadeira revisão daquilo que antes se tinha como verdade:

É crescente também a tendência a realizar estudos mais localizados, que lidem com realidades mais circunscritas e com períodos mais curtos de tempo. Essa tendência tem possibilitado um aprofundamento de certos temas e uma complexificação na compreensão do passado de determinados fenômenos educativos que, anteriormente, eram visualizados apenas panoramicamente.

Considerando a importância do TCC, como forma de pesquisa para os acadêmicos de Pedagogia da Universidade Estadual de Londrina, busca-se nesses trabalhos compreender um pouco sobre a história e identidade do curso, pois partese da premissa de que as pesquisa em História da Educação, nas últimas décadas, têm ampliado seu horizonte de pesquisa, buscando com isso dar voz aos que, por muito tempo, foram silenciados. Para Lopes e Galvão (2005), pesquisas recentes vêm valorizando, como exemplo, o ambiente interno das instituições: as pinturas; os desenhos; as fotografias, bem como as produções discentes e da comunidade escolar em geral.

Visando contribuir para a disseminação das pesquisas oriundas dos TCC, a Coordenação e vice-coordenação do TCC têm publicado em formato digital e isso facilita e acelera a leitura e coleta dos dados, com exceção do ano de 2008, que se encontra disponível no LEPHE. Para o levantamento dos dados, como já citado acima, procedeu-se com a elaboração de uma ficha catalográfica, considerando as informações sobre autor, título e orientador divididos por área de interesse.

A identificação das temáticas foi realizada, por meio do título dos trabalhos, entendendo que o título deve corresponder, o máximo possível, ao conteúdo da investigação que é apresentada. Nos casos em que esta identificação não foi possível pelo título, procede-se com a leitura do resumo. Para explanar melhor a produção discente e o interesse específico em cada área, elaborou-se o quadro abaixo para demonstrar numericamente os resultados alcançados.

Importante assinalar que a área de Formação de Professores se desdobra, após 2011, em duas outras áreas: Anos Iniciais e Educação Infantil, por conta da reorganização curricular que acontece no curso de Pedagogia naquele período. As sete áreas, que passam a compor o curso, têm caráter administrativo e pedagógico, considerando que constituem especificidades e conjunturas próprias.

O Quadro 1 apresenta a quantidade de TCC produzidos em cada ano por área, compreendidos entre 2008 e 2016, totalizando 664 trabalhos. Observa-se que a produção e apresentação dos trabalhos não foi homogênea, ao longo dos anos, tendo um pico maior de TCC, em 2012, com 121 títulos defendidos. Isso pode ser explicado levando-se em consideração o número de alunos no curso, oscilando entre os desistentes e aqueles que ficam retidos. O TCC é disponibilizado na página no ano em que esse foi defendido e por isso, tem-se variação de defesas ao longo dos anos.

Quadro 1 - Quantidade TCC Curso de Pedagogia - Ano/Área

\begin{tabular}{|l|c|c|c|c|c|c|c|c|c|}
\hline \multicolumn{1}{|c|}{ Área } & $\mathbf{2 0 0 8}$ & $\mathbf{2 0 0 9}$ & $\mathbf{2 0 1 0}$ & $\mathbf{2 0 1 1}$ & $\mathbf{2 0 1 2}$ & $\mathbf{2 0 1 4}$ & $\mathbf{2 0 1 5}$ & $\mathbf{2 0 1 6}$ & Total \\
\hline Didática & 14 & 14 & 16 & 12 & 23 & 13 & 09 & 10 & 111 \\
\hline Filosofia e Educação & 06 & 03 & 04 & 06 & 06 & 03 & 02 & 04 & 34 \\
\hline Formação de professores & 34 & 31 & 24 & 24 & - & - & - & - & 113 \\
\hline História da Educação & 03 & 04 & 04 & 07 & 09 & 06 & 06 & 07 & 46 \\
\hline Psicologia da Educação & 16 & 16 & 19 & 20 & 33 & 11 & 13 & 29 & 157 \\
\hline Política Gestão Educação & 22 & 14 & 15 & 25 & 17 & 13 & 08 & 16 & 130 \\
\hline Anos Iniciais & - & - & - & - & 10 & 13 & 09 & - & 32 \\
\hline Educação Infantil & - & - & - & - & 23 & 01 & 09 & 08 & 41 \\
\hline \multicolumn{1}{|c}{ Total } & $\mathbf{9 5}$ & $\mathbf{8 2}$ & $\mathbf{8 2}$ & $\mathbf{9 4}$ & $\mathbf{1 2 1}$ & $\mathbf{6 0}$ & $\mathbf{5 6}$ & $\mathbf{7 4}$ & $\mathbf{6 6 4}$ \\
\hline
\end{tabular}

Fonte: Dados da pesquisa. 
O Quadro 1 permite analisar em quantidade o número de defesa por área. A área mais procurada nestes anos foi Psicologia da Educação com 157 trabalhos defendidos, que concentram cerca de $24 \%$ do total de trabalhos, seguida da área de Políticas e Gestão da Educação com 130 trabalhos defendidos, que representam 19\% dos trabalhos defendidos. A área de Filosofia e Educação e a área de Anos Iniciais são as menos procuradas pelos discentes, em suas investigações, com 34 e 32 defesas respectivamente, que resultam em apenas $5 \%$ do interesse dos trabalhos defendidos.

\section{Conclusão}

Observar o que os alunos do curso de Pedagogia possuem de interesse de pesquisa, manifestado no momento do seu TCC, revela a inclinação de área do conhecimento dos profissionais que a universidade está formando para atuação na Educação. Dada a amplitude de atuação, que a Educação se propõe a atender, essa manifestação de interesse também revela qual opção curricular do curso tem oferecido aos alunos ou mesmo o interesse despertado neles.

É possível notar, nos resultados obtidos, uma grande concentração de trabalhos com temas relacionados, principalmente, aos aspectos tradicionais e voltados para o mercado de trabalho igualmente tradicional, com vastas bibliografias específicas na área. Por outro lado, assuntos novos e diferenciados e de interesse da área são pouco ou nenhuma vez pesquisados pelos alunos. Muitas vezes se percebe que existem temas "modismos", surge um ou outro trabalho por conta de alguma configuração ou movimento novo da sociedade. Assim como os temas, que se perpetuam e se relacionam à concepção de identidade do profissional da Pedagogia, tal como a Educação Infantil.

A área de Psicologia representar o maior volume de trabalhos, relacionando com a Didática, por exemplo, faz perceber que os questionamentos e interesses dos alunos passam muito mais por questões do desenvolvimento da criança, das problemáticas comportamentais e demais assuntos que a Psicologia pretende dar suporte do que da problematização dos processos didáticos sobre como ensinar e atingir a aprendizagem, que em tese representa a caracterização da atividade docente, o ensino.

Dessa forma, constata-se aqui uma vasta lacuna temática a ser ainda explorada pelos alunos de graduação no curso. Novas tecnologias, novos problemas, gestões e novos espaços de atuação que os profissionais da Pedagogia têm encontrado na sociedade e que pouco são abordados nos TCC. As novas configurações sociais, políticas e econômicas, certamente, apresentarão novos questionamentos ao papel social da Educação e este cenário exigirá que a Educação se posicione, em diversos momentos, dando respostas éticas com base na sua especificidade, que é a constituição da humanidade na espécie humana.

Mesmo com todas suas limitações, o TCC representa parte do conhecimento que o aluno possui de mais recente, quando este sai da universidade para atuar, profissionalmente, na sociedade. Por isso, este trabalho deve possibilitar a abertura de novos caminhos, novas portas e perspectivas para a constituição de uma identidade profissional mais ampla e atualizada, além de propor inquietações para aprofundamento nos estudos, ao apontar que um caminho é a abertura das áreas e análise de cada um dos TCC.

Nesse sentido, posteriormente, entende-se que existe margem para um aprofundamento mais detalhado desta pesquisa, por meio da abertura dos temas e identificação da relação da área com o que de fato se caracteriza como objeto de estudo do trabalho do aluno. É possível refinar essa relação e estabelecer novas perspectivas e olhares sobre o perfil e formação dos alunos do curso de Pedagogia da Universidade Estadual de Londrina em que se propôs realizar uma redefinição destes 664 trabalhos dentro das áreas e uma análise pormenorizada de cada trabalho.

A realização dessa pesquisa contribuiu para novos olhares e reflexões acerca do fazer da história, visto que se partiu da premissa de que todos são sujeitos históricos e que, portanto, constroem e (re)constroem a história e a história da humanidade. Com isso, ao se buscar a história do curso de Pedagogia da UEL, nas abordagens dos discentes, em seus TCC, também se ressalta a importância da pesquisa nos cursos de graduação, pois é por meio dessas que os indivíduos têm contato e constroem conhecimentos científicos, para além daqueles trabalhados em sala de aula.

Os dados elencados apontam que o foco maior das pesquisas dissertou sobre Instrumentos Avaliativos e Produção discente. Diante desses dados e também os objetivos, a priori, faz-se necessário salientar que não foi possível compreender por quais razões os discentes optaram por essas temáticas.

Por fim, esta pesquisa buscou compartilhar e enfatizar a necessidade da pesquisa durante a formação inicial, pois por meio dessa é também possível problematizar e compreender o próprio processo de formação acadêmica em seus amplos aspectos.

\section{Referências}

ABBUD, M.L.M.; FAVARO, M.R.G. Organização curricular do curso de Pedagogia - 50 anos de História. In: ABBUD, M.L.M. et al. 50 anos da Pedagogia: da Faculdade de Filosofia, Ciências e Letras de Londrina à Universidade Estadual de Londrina (1962 a 2012). Londrina: UEL, 2012.

ABBUD, M.L.M.; RIBEIRO, K. O ensino de metodologia do trabalho científico em educação e pesquisa em educação: relato de experiência. In: CONGRESSO NACIONAL DE EDUCAÇÃO, 13. Curitiba, 2015. Anais... Disponível em: $<$ https://educere. pucpr.br/p304/anais.html> Acesso em abr 2018.

BODART, C.N.; TORRES, K.R. A pesquisa como processo de ensino-aprendizagem: uma experiência docente e discente. Rev. Cient. UMC., v.3, n.1, 2018. doi: https://dx.doi.org/10.2139/ ssrn. 3123721

BRASIL. Ministério da Educação. Lei de Diretrizes e Bases - Lei No 9.394 de 20 de dezembro de 1996. Brasília: MEC, 1996.

BRZEZINSKI, I. Pedagogia, pedagogos e formação de 
professores: busca e movimento. Campinas: Papirus, 1996.

CASTRO, C.A. A pesquisa discente nos cursos de graduação em biblioteconomia e ciência da Informação. Transinformação, v.14, n.1, p. 49-53, 2002.

DEMO, P. Cuidado metodológico: signo crucial da qualidade. Soc. Estado, v.17, n.2, p.349-373, 2002.

FREIRE, P. Educar pela pesquisa. São Paulo: Autores Associados, 2003.

GATTI, B. A identidade do pedagogo. Educ. Comp., v.5, n.1, 1993.

GATTI, B. Implicações e perspectivas da pesquisa educacional no Brasil contemporâneo. Cad. Pesq., n.113, p.65-81, 2001.

GONÇALVES FILHO, A.M.; NORONHA, D.P. Panorama temático de trabalhos de conclusão de Curso de Biblioteconomia. Transinformação, v.16, p.59-70, 2004.

LIBÂNEO, J.C. Pedagogia e pedagogos, para quê? São Paulo: Cortez, 1998.

LOPES, E.M.T.; GALVÃO, A.M.O. História da Educação. Rio de Janeiro; DS\&A, 2005.
MARAFELLI, C.M.; RODRIGUES, P.A.M.; BRANDÃO, Z. A formação profissional dos professores: um velho problema sob outro ângulo. Cad. Pesqui., v.47, n.165, p.982-997, 2017. doi: http://dx.doi.org/10.1590/198053144293.

MARTINS, M.F.; VERANI, A. Professor e pesquisador: considerações sobre a problemática relação entre ensino e pesquisa. Rev. Diálogo Educ., v.12, n.37, p.647-680, 2012.

SAVIANI, D. Pedagogia, o espaço da educação na Universidade. Cad. Pesq., v.37, n.130, p.99-134, 2007.

NÓVOA, A. Apresentação. In: CAMBI, F. História da Pedagogia. São Paulo: UNESP, 1999.

SILVA, C.S.B. Curso de Pedagogia no Brasil: história e identidade. Campinas: Autores Associados, 2006.

UNIVERSIDADE ESTADUAL DE LONDRINA. Projeto Político Pedagógico do Curso de Pedagogia da Universidade Estadual de Londrina, Londrina: UEL, 2010.

VIEIRA, S.R. Docência, gestão e conhecimento. Conceitos articuladores do novo perfil do Pedagogo instituído pela Resolução CNE\CP N. 01\2006. Rev. HISTEDBR, n.44, p.131155, 2011. 